\title{
ARTIGO EXPERIÊNCIAS SUBNACIONAIS EM POLÍTICAS DE PROMOÇÃO DA INDÚSTRIA DE DEFESA: O CASO DO RIO GRANDE DO SUL
}

Christiano Cruz Ambros ${ }^{1}$

\section{Introdução}

Este artigo tem como objetivo principal apresentar iniciativas do Governo do Estado do Rio Grande do Sul para a promoção da indústria de defesa gaúcha nos últimos anos. As entidades subnacionais tem um importante papel para o fortalecimento da indústria de defesa nacional e, por meio da formulação e implementação de políticas públicas bem definidas, são capazes de exercer a função de facilitadores e catalisadores das iniciativas nacionais em nível local.

A construção de estratégias para o desenvolvimento da indústria de defesa, assim como a capacidade de instrumentalizar-se para executar as ações planejadas, não é exclusividade dos estados e províncias de países ricos e industrializado. Pelo contrário, existem diversos exemplos de como as entidades subnacionais, em países em desenvolvimento, trabalham em conjunto com o Estado Nacional para fortalecer a indústria de defesa do país.

Nesse sentido, este artigo busca trazer exemplos que demonstrem as diversas políticas públicas que podem ser implementadas por entes subnacio-

I Analista Internacional na Secretaria do Desenvolvimento Econômico, Ciência e Tecnologia (SDECT) do Estado do Rio Grande do Sul. Doutor em Ciência Política pela Universidade Federal do Rio Grande do Sul (UFRGS), Mestre em Ciência Política e bacharel em Relações Internacionais pela mesma universidade. Também possui Pós-Graduação Lato Sensu em Economia e Políticas de Promoção do Desenvolvimento pela UFRGS. As informações aqui apresentadas são de inteira responsabilidade do autor e não representam o posicionamento institucional da Secretaria do Desenvolvimento Econômico, Ciência e Tecnologia (SDECT) do Estado do Rio Grande do Sul. E-mail: chrisambros@gmail.com. 
Experiências subnacionais em Políticas de Promoção da Indústria de Defesa: o caso do Rio Grande do Sul

nais tanto em países desenvolvidos (Austrália, Canadá e França) quanto em desenvolvimento (África do Sul, Índia e México), comparando-as com o que vem sendo feito no caso brasileiro. Não se objetiva aqui fazer uma comparação sistemática e delineada com fins a identificar relações causais ou correlacionais entre variáveis. Muito menos ambicioso que isso, nossa meta aqui é simplesmente ilustrar o argumento principal proposto.

Para a escolha dos casos, nos utilizamos do modelo piramidal de Bitzinger (20I5) como instrumento analítico da hierarquia internacional da indústria de defesa. Assim, os casos exemplificados representam porções distintas da pirâmide organizacional proposta pelo autor, cumprindo nossa intenção de trazer exemplos com realidade bastante diferentes entre si para o estudo. A França é compreendida no segundo grupo em uma classificação das capacidades da indústria de defesa nacional, que comporta seis grandes categorias, onde os Estados Unidos estão isolados no primeiro grupo. A capacidade tecnológica francesa seria próxima da dos EUA, contudo sua base industrial e seus gastos em P\&D são relativamente menores. A Austrália e o Canadá estariam no terceiro grupo, pois são consideradas economias avançadas com um tecido industrial militar tecnologicamente consolidado, mas focada em nichos específicos, diferentemente da França que domina um leque muito mais amplo de tecnologias de defesa. Índia estaria no quarto grupo, dado que é um país com capacidades industriais e tecnológicas em expansão e que procura alcançar o máximo de independência possível no fornecimento de armamentos, criando uma larga base tecnológica para sua indústria de defesa. África do Sul e Brasil estariam em uma quinta categoria, pois possuem uma base industrial de defesa relativamente pequena e com tecnologia limitada, mas, ao mesmo tempo, mantêm pretensões de ter capacidades em diversos segmentos para sustentar seu status de potência regional. Finalmente, o México se encontraria no sexto e último grupo, pois possui capacidades produtivas na indústria de defesa muito limitadas e de baixa intensidade tecnológica, concentrando seus esforços em nichos específicos, como a montagem sob licença de sistemas de armas estrangeiros menos complexos.

A premissa teórica que perpassa este artigo é que a indústria de defesa, além de essencial para a defesa nacional, pode auxiliar na estratégia de endogenização de tecnologias avançadas, pilar fundamental para o desenvolvimento econômico de um país. Consideramos que a Indústria de Defesa é estratégica para qualquer país que deseja manter sua soberania e sua autonomia no século XXI e é variável-chave para a composição do Poder Nacional (Tellis et al. 2000). Assim, "o apoio estatal às indústrias de defesa se justifica, do ponto de vista estratégico, porque uma Base Industrial de Defesa (BID) desenvolvida possibilita ao Estado o domínio de capacidades tecnológicas pró- 
prias, conferindo-lhe um poder adicional de peso perante o sistema internacional" (Mota e Rodrigues 20I2, 3).

Entretanto, a BID também é importante em seus aspectos de estruturação econômica e tecnológica "que estão relacionados ao domínio de tecnologias sensíveis, muitas com caráter dual, e à geração de inovação, de empregos de alta qualificação e de exportações de elevado valor agregado" (Melo 20I5, 26). Dessa forma, faz sentido que a indústria de defesa seja um dos eixos prioritários da estratégia de desenvolvimento econômico e tecnológico de uma região. Para o Estado atuar de maneira transformadora no tecido industrial de um país ou de uma região subnacional, é condição necessária o desenvolvimento de uma política industrial robusta. É nesse sentido que as políticas públicas voltadas para o desenvolvimento da BID precisam estar alinhadas com a política industrial ampla do Estado.

Este artigo, além desta breve introdução, está dividido da seguinte forma: i) na primeira seção, discutimos o conceito de política industrial de defesa e as dimensões de sua implementação; ii) posteriormente, são trazidos exemplos de experiências subnacionais na formulação e implementação de iniciativas de promoção da indústria de defesa local; e iii) na terceira seção, apontamos as iniciativas do Governo do Estado do Rio Grande do Sul para o fortalecimento da indústria de defesa gaúcha. Finalmente, a última seção destina-se às considerações finais.

\section{Política Industrial de Defesa}

A política industrial de defesa, segundo Hall, Markowski \& Wylie (20I0), complementa as políticas de aquisição no sentido de que é desenhada para encorajar ou direcionar investimentos nas capacidades industriais domésticas necessárias se as aquisições forem demandar fornecimento local. Um país pode perseguir uma política estatal que julgue necessário que a indústria local seja capacitada a produzir os materiais de defesa, seja para manter a soberania operacional de suas forças armadas, seja por razões econômicas mais abrangentes. Portanto, políticas industriais de defesa estão prioritariamente voltadas para o estabelecimento e manutenção de fornecimento nacional e opções de suporte para as Forças Armadas.

As Políticas Industriais de Defesa tornam-se relevantes se existe uma decisão em nível estratégico de confiar em maior ou menor extensão, no momento atual ou no futuro, nos fornecedores nacionais para fabricar ou apoiar as capacidades domésticas de defesa. O grande objetivo de uma política industrial de defesa é assegurar a disponibilidade, confiabilidade e custo-benefício das fontes 
Experiências subnacionais em Políticas de Promoção da Indústria de Defesa: o caso do Rio Grande do Sul

nacionais de fornecimento de materiais de defesa. Entretanto, segundo Hall, Markowski e Wylie (20I0), esses objetivos podem ser conflituosos entre si, uma vez que a disponibilidade de fornecedores nacionais pode depender de grandes investimentos em novas fábricas e habilidades, desviando recursos nacionais de outras áreas. A pequena escala produtiva de alguns países pode ser muito custosa e a disponibilidade de negócios relacionados à defesa dependerá de altas barreiras para importação de produtos de defesa estrangeiros. Estas questões impactam no custo-benefício da produção local. Por outro lado, depender de importações impacta na confiabilidade das fontes de fornecimento em tempos de crise e conflagração.

Funcionalmente, uma política industrial de defesa estabelece as diretrizes sobre como i) estabelecer, manter e proteger as capacidades domésticas industriais requeridas; ii) assegurar cadeias de suprimentos suficientemente confiáveis para as capacidades industriais requeridas; iii) manter a viabilidade e prontidão dos fornecedores nacionais preferenciais para atingir os requerimentos das demandas militares - e desenvolver arranjos de salva-guarda se existir perigo de falência do fornecedor; e iv) gerenciar os custos relacionados com as políticas de conteúdo local.

Além da garantia de manutenção da capacidade industrial operacional para produção de materiais de defesa em um país, uma política industrial de defesa muitas vezes também é utilizada para atingir fins econômicos mais amplos, como emprego, inovação e balança de pagamentos. Em relação à utilização de políticas industriais de defesa como estratégia de desenvolvimento econômico por parte dos governos, há diversos argumentos prós e contras, especialmente no que se refere aos processos de spin-off de tecnologias militares para os mercados civis, ao spillover de conhecimento de técnicos e cientistas ligados à inovação militar, e aos impactos diretos da indústria de defesa no PIB e nas exportações.

Uma vez que se decide desenvolver uma política industrial de defesa, ou seja, se decide politicamente arcar com os custos de não buscar necessariamente as opções de preços mais competitivos no mercado internacional em prol de garantir determinada participação da indústria nacional, as estratégias de aquisição variam em quatro possibilidades básicas (Hall, Markowski e Wylie 20Io, I76ı80): i) substituição de importações com margens de preferência doméstica, onde se admite que empresas locais garantam que seus produtos sejam adquiridos mesmo que estejam acima do preço internacional até determinado percentual; ii) substituição de importações com políticas de conteúdo local, em que se exige que a empresa estrangeira fornecedora produza certa fração do valor do contrato em território nacional ou subcontrate empresas nacionais; iii) substituição de importações com compensações (offset), em que certa porção do valor contratado

298 Austral: Revista Brasileira de Estratégia e Relações Internacionais v.7, n.14, Jul./Dez. 2018 
exige contrapartidas do país da empresa estrangeira, seja a partir de transferência de tecnologia, acordos comerciais, etc.; e iv) acordos de divisão de trabalho em aquisições de multinacionais, em que se busca explorar vantagens competitivas entre os países parceiros ou exigir demandas altas para se atingir economia de escala.

Segundo Berkok, Penney e Skogstad (2012), existem três lógicas principais entre os países para desenhar sua política industrial de defesa, quais sejam: i) por um lado, a lógica de substituição de importações busca desenvolver a indústria doméstica para diminuir a dependência estratégica e econômica por produtos de defesa de países estrangeiros. A ferramenta mais eficiente para isso seriam as próprias políticas de aquisições das Forças Armadas, que serviriam como instrumentos promotores por demanda. Os governos podem adquirir equipamentos militares diretamente da indústria nacional, ou utilizar-se de acordos de offset para exigirem co-produção doméstica ou produção nacional licenciada. Além disso, uma robusta coordenação entre o governo e a indústria nacional facilitaria a substituição de importações, na medida em que as empresas consigam fazer ajustes e adaptações de longo-prazo para lidar com as necessidades das Forças Armadas Nacionais; ii) por outro lado, a lógica de desenvolvimento da capacidade exportadora busca capacitar a indústria nacional a inserir-se nas cadeias de valor global, sendo que seu núcleo está em políticas de promoção da oferta. Essas políticas são desenhadas para permitir que as empresas nacionais consigam inserir-se mais facilmente no mercado global, dando a elas vantagens competitivas em disputas por contratos de Forças Armadas estrangeiras. Entre os principais instrumentos estão a disseminação de informações, coordenação, desenvolvimento e retenção de talentos, apoio às pequenas e médias empresas, e, não raro, suporte direto (subsídios, lobby político, barganhas diplomáticas) do governo para promover sua indústria de defesa em outros países; e iii) finalmente, aponta-se que é possível uma combinação de ambas as lógicas.

Dentro dessas duas abordagens, Berkok, Penney e Skogstad (2012) identificaram seis grandes dimensões de políticas públicas que os governos utilizam para atingir suas metas: I. Dimensão de coordenação entre governo e a Indústria de Defesa; 2. Dimensão de promoção e apoio à Pesquisa e Desenvolvimento (P\&D); 3 . Dimensão de apoio às Pequenas e Médias empresas (PMEs); 4. Dimensão de Suporte à inserção na cadeia global e valor (CGV);

2 Conforme afirma Oliveira $(2015,38)$, "o comércio internacional vem crescendo em média $5,4 \%$ anualmente durante os últimos vinte anos, ao mesmo tempo em que passa por profundas transformações em decorrência das novas formas de organização e coordenação da produção industrial. A cadeia produtiva de bens, que anteriormente concentrava-se dentro de um determinado país e na maioria das vezes nas mãos de uma única empresa, hoje se encontra dispersa geograficamente e fragmentada em diversas etapas, nas chamadas "cadeias globais de valor (CGV)"”. A internacionalização das cadeias de valor também influenciou a estrutura das 
Experiências subnacionais em Políticas de Promoção da Indústria de Defesa: o caso do Rio Grande do Sul

5. Dimensão de criação de ambientes de promoção da competitividade; e 6. Dimensão de Offset?.

\section{Dimensão de Coordenação entre Governo e Indústria de Defesa}

Em relação às políticas de coordenação entre governo e indústria de defesa, é importante apontar as dificuldades que o governo pode encontrar para adquirir equipamentos dentro dos prazos requisitados se não existirem empresas nacionais prontas para satisfazer tal demanda. Às empresas, por outro lado, é um desafio manter empregados e capital de maneira eficiente em um mercado no qual a demanda por equipamentos militares não costuma ser constante, mas sim esporádica e instável. Segundo Berkok, Penney e Skogstad $(2012,55)$, políticas que aumentem a coordenação entre o governo e a indústria podem aliviar essas pressões e assegurar um setor industrial de defesa mais estável. Essas políticas podem auxiliar na abordagem da substituição de importações, uma vez que pode ser mais atraente comprar da indústria nacional, já que as empresas nacionais podem estar melhor preparadas para satisfazer a demanda das Forças Armadas do país. Além disso, esse tipo de política auxilia a criar uma base de informações sobre a própria indústria nacional, de forma que os formuladores de políticas de aquisição e gerentes de projetos estratégicos possam direcionar de maneira mais efetiva as demandas para as empresas nacionais.

Como exemplo, os autores mencionam que a coordenação entre o governo de Israel e sua Indústria de Defesa se dá muito a partir dos sistemas de Pesquisa \& Desenvolvimento de maneira permanente, ou seja, independente de haver um grande projeto âncora. A Coréia do Sul, por sua vez, estabeleceu

indústrias de defesa. Segundo Dunne (2009, 27), "além das compras entre países de produtos finais, as companhias também estão mudando suas cadeias de fornecimento, como é o exemplo das compras da BAE System na África do Sul. O aumento dos acordos de offset encorajou este desenvolvimento e deu aos países importadores a oportunidade de consolidar mercados de nicho ao fazer parte da cadeia de suprimentos dos grandes produtores internacionais". O autor também coloca que os governos estão reconhecendo cada vez mais os altos custos do P\&D para tecnologias avançadas de defesa e que a viabilidade de produção de pequenos países passa por economias de escala que só são possíveis através da colaboração internacional e arranjos industriais cooperativos $(2009,27)$.

3 Quando os países decidem por fazer uma compra para suas Forças Armadas de algum fornecedor estrangeiro, é relativamente usual que se exija algum tipo de compensação, também chamada de offset. Conforme a Portaria Normativa nffl 764/ MD/2002 dispõe, offset é "toda e qualquer prática compensatória acordada entre as partes, como condição para a importação de bens, serviços e tecnologia, com a intenção de gerar benefícios de natureza industrial, tecnológica e comercial" (Brasil 2002, I2). Dessa forma, o fator determinante da possibilidade de offset (compensação) é o poder de compra do país importador.

300 Austral: Revista Brasileira de Estratégia e Relações Internacionais v.7, n.14, Jul./Dez. 2018 
um sistema de "Equipe Integrada de Projetos" (Integrated Project Team), composta por civis e militares, destinado a supervisionar e coordenar as iniciativas de aquisição e prover sugestões de aprimoramento ao planejamento, orçamento e confiabilidade do projeto. Já o Reino Unido possui um programa de pré-qualificação de algumas empresas para licitações futuras, preparando-as para lidar com suas demandas.

\section{Dimensão de Promoção e Apoio a P\&D}

As Políticas de promoção e apoio a P\&D geralmente se justificam na percepção de que muitos avanços tecnológicos resultam do investimento na indústria de defesa e de que haveria transbordamentos para outros setores da economia. Mais do que isso, segundo Berkok, Penney e Skogstad (2012, 57), um país que investe de forma sistemática em empresas que desenvolvem novas tecnologias espera penetrar no mercado global e posicionar sua indústria na cadeia global de fornecimento. Existe uma crescente demanda por bens de alta tecnologia, e um país que atinge determinadas fronteiras tecnológicas pode sustentar um forte setor exportador. Além disso, se as empresas nacionais não possuem o know-how tecnológico e industrial para desenvolver e produzir armamentos avançados, o governo precisará importar de outros países. Assim, investimentos em $\mathrm{P} \& \mathrm{D}$ respondem tanto à abordagem da substituição de importações quanto da promoção de exportações.

A política de apoio a P\&D na Coréia do Sul aposta muito nos acordos de coprodução em defesa no intuito de garantir a transferência de tecnologia, buscando desenvolver capacidades produtivas domésticas em áreas que não possui vantagens comparativas. Já a Austrália provê financiamento subsidiado a propostas inovadoras e de alto risco de Pequenas e Médias empresas que contenham alto grau tecnológico e que estejam alinhadas ao Programa de Prioridades de Capacitação Industrial.

\section{Dimensão de Apoio às Pequenas e Médias Empresas (PMEs)}

As políticas de apoio às pequenas e médias empresas (PMEs) começam a ser desenvolvidas a partir do diagnóstico de uma questão já debatida nesta tese: a consolidação da indústria global de defesa em poucos prime contractors multinacionais e as restrições de entrada ao mercado internacional. Considerando que é muito difícil para empresas deste porte serem notadas por grandes integradores, dificultando assim sua entrada na cadeia global de 
Experiências subnacionais em Políticas de Promoção da Indústria de Defesa: o caso do Rio Grande do Sul

suprimentos, políticas que promovam assistência às PMEs podem auxiliá-las a se tornar exportadoras. Conforme aponta Berkok, Penney e Skogstad (20I2, 58), ao se tornarem mais eficientes e garantirem maior sustentabilidade, elas podem tanto fornecer para as Forças Armadas nacionais quanto garantirem espaço na cadeia global a partir de parcerias estratégicas, seja com prime contractors, seja com PMEs estrangeiras. Além disso, o incentivo às PMEs está relacionado com o imperativo estratégico da capacidade de mobilização do tecido econômico e social de um país em situações de emergência nacional, dada a maior capilaridade que as PMEs têm na sociedade em comparação com grandes empresas.

A Austrália desenvolveu o Programa de Demonstração de Capacidades e Tecnologias (Capability and Technology Demonstrator Program) que possibilita que PMEs exibam suas potencialidades às grandes empresas nacionais e internacionais e contatem governos estrangeiros. Na Coréia do Sul, há vários incentivos para que PMEs entrem no mercado de defesa, desde que, como contrapartida, tenham por objetivo de longo prazo serem competitivas internacionalmente. Já em Israel, a maior parte da sua base industrial de defesa é composta por empresas relativamente grandes e o setor de defesa conta com poucos novos entrantes. Em geral, quando há algum tipo de apoio específico às PMEs, se dá através de subsídios para P\&D.

\section{Dimensão de Suporte à inserção na cadeia global de valor (CGV)}

As políticas de suporte à inserção na CGV compreendem as iniciativas às PMEs, e também os incentivos às grandes empresas, pois as vendas diretamente a outros países geralmente é feita em negociação de governo a governo (gov-to-gov). Assim, essas políticas geralmente lidam com a regulação das exportações de produtos de defesa, com iniciativas de marketing dos produtos nacionais, com facilitação de negociação com governos estrangeiros e empresas multinacionais e com linhas especiais de crédito para a exportação.

Aproximadamente $70 \%$ de todos os sistemas de armas produzidos em Israel são exportados, e isso se faz possível, em partes, graças ao forte apoio governamental no marketing internacional dos produtos de defesa israelenses, às missões internacionais lideradas pelo governo e à pró-atividade das embaixadas israelenses em mercados de defesa prósperos. Já o governo do Reino Unido age mais no momento anterior ao ato da exportação. Ao definir as tecnologias específicas que pretendem produzir domesticamente, os ingleses criam fundos de pesquisa específicos que possibilitam a criação de produtos tecnologicamente avançados. A partir da compra dos produtos ingleses 
por suas Forças Armadas, o governo inglês implicitamente afirma a qualidade dos produtos, facilitando de maneira significativa as suas exportações.

\section{Dimensão para Criação de Ambientes de Promoção da Competitividade}

Uma etapa importante para a sustentação de uma base industrial de defesa nacional é o estabelecimento de um ambiente em que as empresas desejem investir. Para isso, é necessário atentar a quatro fatores: i) desenvolvimento de mão de obra técnica e especializada; ii) regulamentações claras de acesso ao mercado (normatizações e certificações); iii) regime tributário competitivo; e iv) linhas de financiamento adequadas ao setor de defesa.

A indústria de defesa é geralmente muito técnica, requerendo uma força de trabalho altamente especializada. Assim, são necessários investimentos públicos para o desenvolvimento de escolas técnicas, cursos profissionalizantes e cursos superiores voltados para a área de defesa. Segundo Berkok, Penney e Skogstad (2012, 59), as barreiras de entrada no mercado de defesa precisam ser diminuídas, pois lidar com regulações extensas e obscuras podem afastar empreendedores. Além disso, arquiteturas fiscais que possibilitem as empresas de defesa a serem mais competitivas no mercado internacional e linhas de financiamento que compreendam a lógica especial do setor de defesa também são importantes para o estabelecimento de um ambiente próspero de investimentos privados na área.

A Austrália possui um projeto especial de capacitação de mão de obra nas áreas que pretendem manter a capacitação industrial e tecnológica para estimular um ambiente competitivo. Chamado "Capacitando a Indústria de Defesa da Austrália” (Skilling Australia's Defence Industry), este programa oferece bolsas de estudo buscando três objetivos: aprimorar os trabalhadores já empregados na Indústria de Defesa; aumentar a quantidade e qualidade de trabalhadores voltados para áreas prioritárias em defesa; prover fundos para que as próprias empresas de defesa ofereçam atividades de treinamento em áreas onde se identifique falta de recursos humanos com capacidades técnicas, comerciais ou de gestão. Já a abordagem política israelense para promover um ambiente competitivo para o investimento, especialmente o estrangeiro, no país, consiste em permitir que investidores estrangeiros comprem até $49 \%$ de empresas nacionais, com incentivos especialmente no que se refere ao abatimento do valor investido nas exigências de contrapartida. 
Experiências subnacionais em Políticas de Promoção da Indústria de Defesa: o caso do Rio Grande do Sul

\section{Dimensão de Offset}

As políticas de offset vêm sendo amplamente utilizadas por diversos países. Enquanto alguns usam offsets para a criação de empregos ou compensações comerciais para equilíbrio da balança de pagamentos, a maior parte dos países vê neste instrumento oportunidades de transferência de tecnologia. Alguns governos vêm exigindo offsets para todos os contratos acima de determinado valor, geralmente como uma fração do valor do contrato de aquisição.

A política sul-coreana de offset estabelece que $50 \%$ do valor total do contrato deve estar sujeito a compensações, sendo que $60 \%$ dessas compensações devem ser de natureza tecnológica e industrial como co-produção, transferência de tecnologia, investimentos em P\&D e desenvolvimento técnico. Já a política da Suécia é mais restrita, exigindo ıo०\% do valor do contrato em compensações tecnológicas, principalmente elementos de co-produção, sendo que offsets indiretos como investimentos na indústria doméstica ou contrapartidas comerciais são inelegíveis.

Na próxima seção, exemplificaremos experiências subnacionais em políticas de promoção da indústria de defesa tanto em países com um grau de desenvolvimento industrial e tecnológico avançado quanto aqueles com um tecido industrial e um sistema de inovação ainda em desenvolvimento. Ao estudar os casos, utilizaremos o arcabouço conceitual apresentado acima, identificando as políticas de promoção da indústria de defesa apresentadas por Berkok, Penney e Skogstad (20I2).

\section{Experiências subnacionais em Políticas de Promoção da Indústria de Defesa}

As entidades subnacionais têm executado papéis diversos em termos de políticas industriais e promoção da competitividade empresarial em seus territórios. No que se refere especificamente às políticas de promoção da indústria de defesa, diversos exemplos são possíveis de ser citados em diversas partes do mundo, com ações diversas, focadas tanto no apoio ao desenvolvimento de clusters regionais quanto ao fomento de P\&D, entre outras. Nessa seção, abordaremos os casos de estados e províncias de países com um tecido industrial e capacidades tecnológicas desenvolvidas (especificamente, Canadá, França e Austrália), assim como experiências subnacionais em países cujas condições de desenvolvimento são mais similares com as do Brasil 
(como África do Sul, Índia e México).

O Canadá, lar de uma das maiores empresas aeronáuticas do mundo a Bombardier tem no setor aeroespacial uma indústria que gera $\$ 27,2$ bilhões em faturamento e cerca de 90 mil empregos ${ }^{4}$. A indústria aeroespacial concentrada na província de Quebec responde por cerca de 50\% em faturamento do setor no Canadá, com \$I4.4 bilhões em vendas anuais, 40.000 empregos e I90 empresas de pequeno, médio e grande porte5.

Criada em 2006, a Aero Montreal é uma organização que reúne as principais companhias, instituições de pesquisa e educacionais, associações e sindicatos do setor aeroespacial de Quebec, com o objetivo de apoiar o desenvolvimento da cadeia de valor aeroespacial e promover a região como polo de excelência internacional ${ }^{6}$. Além de ser financiada pelos seus membros associados, a Aero Montreal também conta com recursos do Governo da Província de Quebec e do Governo do Canadá. Em 20I4, a Aero Montreal garantiu assistência financeira para três anos de cerca de I,5 milhões de dólares canadenses do governo canadense, no intuito de desenvolver projetos relacionados aumentar a produtividade na cadeia de fornecimento aeroespacial e fortalecer a competitividade e ações de networking no setor?. Da mesma forma, a Aero Montreal também conta com apoio do Governo da Província de Quebec: a Estratégia Aeroespacial de Quebec 2016-2021 destina \$250 milhões em cinco anos para apoiar o desenvolvimento da indústria aeroespacial, diversificar o cluster industrial, acelerar a expansão das PMEs e suportar projetos de inovação, em especial relacionados à tecnologias verdes na aviação ${ }^{8}$.

A indústria aeroespacial francesa é inegavelmente uma potência em âmbito global, sendo o Grupo Airbus o líder na fabricação de aeronaves civis no mundo. Ranqueada em segundo lugar do mundo em termos de faturamento, atrás somente dos EUA, as vendas aeroespaciais anuais francesas alcançaram U\$ 66,2 bilhões em 20I3. Este montante é responsável por 2,42\% do PIB nacional, o maior percentual entre os países líderes na produção ae-

\footnotetext{
4 Aerospace Industries Association of Canada (AIAC). Industry Statistics. http://aiac.ca/industry-statistics/. Acesso em II de julho de 2017.

5 Aero Montreal. Reports and Documents. https://www.aeromontreal.ca/reports-and-documents. html. Acesso em in de julho de 2017.

6 Aero Montreal. Site institucional. https://www.aeromontreal.ca/. Acesso em ro de julho de 2017.

7 Market Wired. “AeroMontreal Receives \$I,584,I50 in Funding from Government of Canada". http://www.marketwired.com/press-release/aero-montreal-receives-I584I50-in-funding-fromgovernment-of-canada-I906355.htm/. Acesso em Io de julho de 2017.

8 Aero Montreal. Québec Government's 2016-2017 Budget. https://www.aeromontreal.ca/releasequebec-government-20I6-I7-budget.html. Acesso em io de julho de 2017.
} 
Experiências subnacionais em Políticas de Promoção da Indústria de Defesa: o caso do Rio Grande do Sul

roespacial. Em 2008, a França exportou 75\% da sua produção aeroespacial, acumulando U\$ 49,7 bilhões em exportações (GARDES et al., 20I5).

Desde meados de 2000 , a França foi remodelando suas políticas industriais e instituindo, dentro de um programa de financiamento nacional, os Polos de Competitividade, explicitamente inspirados no modelo de Porter para a formalização de lações entre autoridades locais, organizações de pesquisa e empresas objetivando o desenvolvimento econômico através da inovação (Gardes et al. 20I5). Assim, em 2005, foi criado o Aerospace Valley, um polo de competitividade bi-regional (Midi-Pyrénées e Aquitaine) dedicado ao setor aeronáutico, espacial e sistemas embarcados. Com objetivos de promover internacionalmente a indústria local, a inovação compartilhada e a competitividade na cadeia de fornecimento, o Aerospace Valley possui uma governança e financiamento tripartite: I/3 é do governo francês; I/3 dos governos regionais; e I/3 de taxas de associação. Atualmente, o cluster conta com mais de 840 membros, entre 80 prime companies, 500 PMEs e uma série de universidades e estabelecimentos de pesquisa. Dessa forma, um terço da força de trabalho francesa alocada no setor aeroespacial está concentrada neste cluster, totalizando em cerca de I25 mil trabalhadores.

A Austrália Meridional, autointitulada o Estado da Defesa na Austrália, é lar de algumas das principais empresas australianas de defesa responsáveis pelos maiores e mais complexos projetos do país, assim como possui uma ampla presença militar e infraestrutura de defesa instalada. Possuidora de estaleiros de porte, a Austrália Meridional conquistou A $\$ 50$ bilhões do programa do Submarino do Futuro para construção no Techport, e mais A\$35 bilhões do programa Fragata do Futuro.

Devido à importância do setor de defesa para o Estado da Austrália Meridional, criou-se a Defence SA, uma agência governamental responsável por lidar com todos os assuntos relativos à indústria de defesa no Estado. Assim, a agência articula os principais atores da defesa, tanto a nível nacional quanto regional, em seu Comitê Gestor, e, trabalhando fortemente em conjunto à indústria local, objetiva atrair investimentos, ampliar oportunidades, apoiar o treinamento de mão de obra especializada e estabelecer infraestrutura científica. Além disso, a agência formulou e está executando a Estratégia da Austrália Meridional para a Defesa 2025, que estabelece as principais diretrizes para o fortalecimento da indústria de defesa no Estado ${ }^{\mathrm{IO}}$.

9 Aerospace Valley. Site institucional. http://www.aerospace-valley.com. Acesso em iI de julho de 2017 .

Io Defence South Australia. South Australia Defence Strategy 2025. http://www.defencesa.com/ about-defence-sa/south-australias-defence-strategy-2025. Acesso em Io de julho 2017.

306 Austral: Revista Brasileira de Estratégia e Relações Internacionais v.7, n.14, Jul./Dez. 2018 
O Departamento de Desenvolvimento do Estado da Austrália Meridional aposta no incremento de inovação e colaboração através da dinâmica de clusterização especializada. De 20I3 a 20I7, o governo do Estado investiu A \$5 milhões de dólares australianos em seis projetos, sendo que dois deles no setor de defesa e aeroespacial ${ }^{\mathrm{II}}$ : a Aliança Australiana Aeroespacial (Australian Aerospace Alliance - AAA) e a Aliança para Veículos Especializados (Specialist Vehicle Alliance - SVA). A primeira se trata de um projeto colaborativo entre o Defence Teaming Centre ${ }^{\mathrm{I} 2}$, a indústria de defesa e o Departamento de Desenvolvimento, com o objetivo de promover as empresas do Estado internacionalmente e de trabalhar com atores chaves da cadeia produtiva para disseminar práticas de manufatura avançada nos processos produtivos. A segunda trata do Projeto de Integração da Indústria de Defesa e Automotiva na Austrália Meridional (South Australian Defence Industry Automotive Integration Project - SADIAIP), que prospecta e facilita a diversificação de empresas automotivas da região para também ofertarem no mercado de defesa, com o objetivo de criar projetos de veículos militares especializados para exportação, especialmente focando o mercado do sudeste asiático.

Entes subnacionais de países com um tecido industrial menos desenvolvido ou com uma infraestrutura de inovação tecnológica relativamente deficiente também são capazes de desenvolver políticas industriais específicas para defesa. Podemos perceber que, nesses casos, as políticas são bastante voltadas para a atração de novos investimentos na cadeia produtiva do setor e para a absorção de tecnologias, especialmente através de programas de offset.

Na África do Sul, Gauteng, a principal província industrial do país, tem um forte programa de atração de investimentos e de apoio a exportações, com participação em feiras e apoiando o marketing internacional das empresas locais. A Cidade de Tshwane, anteriormente chamada de Pretória, é a capital administrativa da África do Sul e uma das maiores cidades da Província de Gauteng. Ela é considerada o hub de desenvolvimento de tecnologias aeroespaciais e de defesa da África do Sul, sediando gigantes industriais sul-africanos como ARMSCOR, DENEL Dynamics e Aerosud. Em agosto de 2013, a Cidade de Tshwane, através da sua Agência de Desenvolvimento Econômico, assinou um acordo de parceria com a Aerospace Industry Support Iniciative (AISI), órgão vinculado ao Departamento de Comércio e Indústria (Department of Trade and Industry -DTI) da África do Sul, no intuito de promover o setor de defesa e aeroespacial, em especial o desenvolvimento de PMEs para

II Australia. Department of State Development - Clusters. http://statedevelopment.sa.gov.au/ industry/innovation/clusters. Acesso em Io de julho de 2017.

I2 O Defence Teaming Centre é uma associação sem fins lucrativos que representa a indústria de defesa da Austrália Meridional. http://www.dtc.org.au. Acesso em io de julho de 20I7. 
Experiências subnacionais em Políticas de Promoção da Indústria de Defesa: o caso do Rio Grande do Sul

fornecer às grandes prime contractors da região. Entre os projetos que este acordo abarca está o Centurion Aerospace Village (CAV).

O Centurion Aerospace Village (CAV) é uma iniciativa do DTI para o desenvolvimento de um cluster específico para a indústria de defesa e aeroespacial nos arredores da Cidade de Tshwane. Seu objetivo é aumentar a competitividade das empresas instaladas para fornecer às cadeias globais de valor através da localização física próxima de grandes players, como a DENEL e a AEROSUD. A ideia é criar um espaço atrativo para empresas internacionais e nacionais do setor da defesa e transformar o CAV em uma plataforma de exportação global. A melhoria da competitividade das empresas viria especialmente da eficiência logística advinda da co-localização, do compartilhamento de serviços e instalações, da possibilidade de treinamento de PMEs e do estímulo ao P\&D compartilhado ${ }^{\mathrm{I} 3}$. Entretanto, há duras críticas ao projeto, pois desde sua inauguração em 2008 foram gastos quase US\$ Io milhões e obtiveram-se pouquíssimos resultados. Atualmente, o Parlamento vem investigando possíveis irregularidades na licitação para terraplanagem do terreno e fraudes e corrupção na relação com a única empresa instalada ${ }^{\mathrm{T}}$.

Outro caso é o estado de Punjab, na Índia. Fortemente alinhado com a política industrial indiana, chamada de Make in Índia, Punjab orientou suas políticas públicas de inovação e atração de investimento para o setor aeroespacial e de defesa. Um dos grandes atrativos utilizados pelo estado é sua forte base de pequenas e médias empresas de engenharia, que contribuem com mais de $15 \%$ das exportações totais de Punjab, além de suas universidades de ponta para engenharia de manutenção de aeronaves. $O$ instrumento mais interessante que eles possuem são programas específicos de auxílio dos programas federais de offset, ou seja, eles conseguem identificar, a partir da sua capilaridade local, as empresas que são capazes de absorver aquele offset, aquela transferência tecnológica que está sendo ocasionada por causa dos grandes contratos que o país está fazendo. Além disso, utilizam competitivos incentivos fiscais para atração de investimentos, promovendo oportunidades

I3 África do Sul. Department of Trade and Industry. CAV Presentation: Portfolio Committee on Trade and Industry CAV CEO, 20I5. https://www.thedti.gov.za/ parliament/ 20I5/CAV.pdf . Acesso em o5 de outubro de 2016.

I4 Ver em The Citzen. "Rgom spent on Centurion Aerospace Village, nothing on site". I7 de setembro de 20I5. http://citizen.co.za/775690/r9om-spent-on-centurion-aero space-villagenothing-on-site/. Acesso em 05 de outubro de 20I6. Também ver em Helfrich, Kim. Nothing happening at Centurion Aerospace Village DA maintains. DefenceWeb, I8 de setembro de 20I5. http://www.defenceweb.co.za/index.php?option=com_con tent\&view=article\&id=40786:noth ing-happening-at-centurion-aerospace-village-da-maintains \&catid=35:Aerospace\&Itemid=I07. Acesso em 05 de outubro de 2016.

308 Austral: Revista Brasileira de Estratégia e Relações Internacionais v.7, n.14, Jul./Dez. 2018 
especialmente no setor de reparo e manutenção de aeronaves ${ }^{15}$.

Em anos recentes, um cluster aeronáutico emergiu no estado de Querétaro, no México. Em 2013, a indústria aeronáutica em Querétaro representava I0\% do produto interno bruto do estado e empregava 5.000 pessoas. $\mathrm{O}$ Aerocluster de Querétaro tem uma média de I7\% de crescimento anual nos últimos dez anos ${ }^{16}$, sendo que, entre i999 e 20i6, o Investimento Externo Direto (IED) para a fabricação de equipamentos aeronáuticos no estado somou cerca de US\$ I bilhão ${ }^{17}$ e contou com investimentos da Bombardier, Airbus, Safran e Aernnova. O cluster, que une empresas nacionais e internacionais, academia e governo estadual e federal, se desenvolveu a partir de ações integradas entre o Governo do México e o de Querétaro focadas na promoção do investimento estrangeiro, desenvolvimento tecnológico regional, fortalecimento de fornecedores locais e formação de capital humano ${ }^{\mathrm{I}}$. Atualmente, o cluster já mantém sua governança de forma sustentável, contando com apoio governamental para projetos específicos ${ }^{19}$. A partir de uma robusta articulação entre os atores do cluster, inclusive com cruzamentos acionários entre empresas, se criou um ambiente propício para o investimento em P\&D, trazendo um nível de especialização setorial e posicionando o cluster como primeiro para atração de investimentos aeronáuticos no México.

Finalmente, no Brasil, também temos experiências no setor de defesa de políticas de desenvolvimento implementadas a partir de iniciativas subnacionais. Na dimensão da organização e otimização industrial, uma das principais políticas desenvolvidas são as de apoio integrado aos arranjos produtivos locais. Arranjos Produtivos Locais (APLs), termo que significa algo se-

I5 Pujab. "Invest in Punjan Aerospace and Defence sector". Disponível em: http:// investpunjab.gov.in/Content/documents/Collateral/AerospaceandDefence_Col.pdf. Acesso em 03 de agosto de 20I7. Ver também HINDUSTAN TIMES, "Young entrepreneur to set up Punjab's Ist defence, aerospace parts unit”. Disponível em: http://www.hindustantimes. $\mathrm{com} /$ punjab/young-entrepreneur-to-set-up-punjab-s-first-defence-aerospace-parts-unit/storyFfWVpk8vllacU2dXfwp6IK.htm. Acesso em o3 de agosto de 2017.

I6 Índice Político. "Ubican a Querétaro como el Paraíso para la Industria Aeroespacial de México". http://www.indicepolitico.com/ubican-a-queretaro-como-el-paraiso-para-la-industriaaeroespacial-de-mexico/. Acesso em II de agosto de 2017 .

I7 El Financiero. "Crece I70\% la IED de equipo aeroespacial em Querétaro". Disponível em: http://www.elfinanciero.com.mx/bajio/crece-I7o-la-ied-de-equipo-aeroespacial-en-queretaro. html. Acesso em ir de agosto de 2017.

I8 Aerocluster Queretaro. "Mapa de ruta del sector aeroespacial de la región de Queretaro". http://aeroclusterqueretaro.mx/images/PDF/Mapa-de-ruta-del-Sector-Aeroespacial-de-laRegin-de-Quertaro-c_portada-IO0220I6.pdf. Acesso em II de agosto de 2017.

I9 El Financiero. "El cluster aeronáutico de Queretaro ya vuela solo". http://www.elfinanciero. com.mx/economia/el-cluster-aeronautico-de-queretaro-ya-vuela-solo.html. Acesso em II de agosto de 2017 . 
Experiências subnacionais em Políticas de Promoção da Indústria de Defesa: o caso do Rio Grande do Sul

melhante ao cluster, são aglomerações de empresas, localizadas em um mesmo território, que apresentam especialização produtiva e mantêm vínculos de articulação, interação, cooperação e aprendizagem entre si e outros atores locais, intensificando a partir das redes de relação e vínculo a competitividade dos participantes. Em agosto de 2004 foi instituído o Grupo de Trabalho Permanente para Arranjos Produtivos Locais - GTP APL através da Portaria Interministerial nffl 200, de 02 de agosto de 2004. Envolvendo dezenas de instituições governamentais e não-governamentais, o GTP APL é coordenado pelo Ministério da Indústria, Comércio Exterior e Serviços, por meio da Coordenação-Geral de Arranjos Produtivos Locais e possui a "atribuição de elaborar e propor diretrizes gerais para a atuação coordenada do governo no apoio a arranjos produtivos locais em todo o território nacional" ${ }^{20}$.

As políticas públicas de desenvolvimento de APLs costumam ser bastante federalizadas, tendo como ente fomentador por vezes a União, por vezes os estados ou municípios. Especificamente no que se refere ao setor de defesa e aeroespacial, encontramos no exemplo do APL Aeroespacial e Defesa (Brazilian Aerospace Cluster - BAC), centrado em São José dos Campos / SP, a consolidação de um movimento de cooperação histórico entre empresas, universidades e Forças Armadas que remonta das origens do setor aeroespacial brasileiro com o estabelecimento do Departamento de Ciência e Tecnologia Aeroespacial (DCTA) e do Instituto de Tecnologia Aeronáutica (ITA) dentro da Força Aérea Brasileira, respectivamente em i945 e I950. Tendo um formato de APL, o BAC foi formado em 2009 e reúne cerca de 120 empresas de seis estados brasileiros, porém, a maior parte delas (60\%) está sediada em São José dos Campos, inclusive dentro do Parque Tecnológico de São José dos Campos. A empresa âncora do projeto é a Embraer e, ao todo, são quase 25 mil postos de trabalho com faturamento anual de U\$ 7 bilhões ${ }^{21}$. Existem vários benefícios oferecidos às empresas associadas ao APL para aumentar sua competitividade e oportunidades, como programas de internacionalização, capacitação e obtenção de certificações, assim como a participação em feiras nacionais e internacionais, missões comerciais, rodadas de negócios e formação de consórcios. Este APL é um exemplo em que o ente fomentador é a União, através de programas da APEX Brasil e da ABDI, sendo o ente articulador o Centro para a Competitividade e Inovação do Cone Leste Paulista $(\text { CECOMPI })^{22}$.

20 Observatório Brasileiro de APLs. Site institucional. http://portalapl.ibict.br/menu/itens_ menu/gtp_apl/gtp_apl.html. Acesso em: 22 de novembro de 2016.

2I Parque Tecnológico de São José dos Campos. Site Institucional. http://www.pqtec.org.br/ conheca-o-parque/quem-somos.php. Acesso em 23 de novembro de 2016.

22 CECOMPI. Aerospace Cluster. http://www.cecompi.org.br/aero/en/aerospace-cluster.

310 Austral: Revista Brasileira de Estratégia e Relações Internacionais v.7, n.14, Jul./Dez. 2018 
A ABDI possui um interessante projeto em parceria com o Parque Tecnológico de São José dos Campos e a EMBRAER, o Programa de Desenvolvimento da Cadeia Aeronáutica (PDCA). O programa auxilia empresas da cadeia de fornecedores da Embraer a se capacitarem técnica e tecnologicamente para garantirem seu espaço na cadeia de fornecimento da empresa nacional e se integrarem a cadeias internacionais de valor. O PDCA, iniciado em 20I4, conseguiu aumentar a produtividade das empresas, reduzir custos e desperdícios, diminuir riscos empresariais e elevar o grau de exportação dos produtos. As novas tecnologias dominadas com o Programa permitiram às empresas participarem da cadeia do jato militar de transporte tático KC-39o e da nova família de jatos comerciais E-Jets E2. Em 20ıo, o setor produzia cerca de 32 mil tipos de peças diferentes e, já em 20I5, este portfólio de peças mais que dobrou ${ }^{23}$.

O APL Polo de Defesa de Santa Maria / RS, por sua vez, é um APL cujos recursos financeiros provêm do Governo do estado. Através do Programa Estadual de Fortalecimento das Cadeias e Arranjos Produtivos Locais, coordenado pela Agência Gaúcha de Desenvolvimento e Promoção do Investimento (AGDI), recursos são repassados à Agência de Desenvolvimento de Santa Maria (ADESM) para gerenciar as ações conjuntas do APL ${ }^{24}$. As principais ações do APL são de articulação entre os entes locais e o Governo Federal e as Forças Armadas, no intuito de promover as iniciativas do Polo de Defesa, assim como participar de feiras e missões nacionais e internacionais para a promoção comercial das empresas do setor e de ações de mobilização da BID do Estado 25 .

Finalmente, como exemplo de iniciativa fomentada por entes municipais, temos o APL de Defesa do Grande ABC, coordenado pela Agência de Desenvolvimento Econômico da Grande $\mathrm{ABC}$, cujo principal patrocinador é o Consórcio Intermunicipal do Grande $\mathrm{ABC}$, composto pelos municípios de Santo André, São Bernardo do Campo, São Caetano do Sul, Diadema, Mauá, Ribeirão Pires e Rio Grande da Serra ${ }^{26}$. Desde a grave crise que o setor auto-

Acesso em 23 de novembro de 2016.

23 Agência Brasileira de Desenvolvimento Industrial. "Programa estimula inovação na indústria aeronáutica”. http://www.abdi.com.br/Paginas/noticia_detalhe.aspx?i=4097. Acesso em or de dezembro de 2016 .

24 A Razão. "Polo de Defesa de Santa Maria é reconhecido como APL". http://www.arazao. com.br/noticia/70693/polo-de-defesa-de-santa-maria-reconhecido -como-apl/. Acesso em 23 de novembro de 2016.

25 Observatório Brasileiro de APLs. "Plano de Ação do Polo de Defesa de Santa Maria”. http:// portalapl.ibict.br/export/sites/apl/galerias/Biblioteca/APL_de_Defesa_-_Plano _de_Axo_do_ Polo_de_Defesa_de_Santa_Maria_20I5.pdf. Acesso em 23 de novembro de 2016.

26 Agência de Desenvolvimento Econômico do Grande ABC. Site Institucional. http://www. 
Experiências subnacionais em Políticas de Promoção da Indústria de Defesa: o caso do Rio Grande do Sul

motivo da região vem passando, as prefeituras locais procuram alternativas de desenvolvimento regional. Assim, identificaram no setor de defesa a possibilidade de retomar o crescimento da indústria local, focando o APL para a diversificação da produção e complementação de linhas em indústrias não tradicionais da defesa.

\section{Rio Grande do Sul: iniciativas de promoção do setor de defesa, segurança e aeroespacial}

Devido sua posição geográfica fronteiriça, historicamente o Rio Grande do Sul conta com numerosa concentração de militares em seu território. No município de Rio Grande, no sul do estado, está localizada a sede do $5^{\circ}$ Distrito Naval da Marinha do Brasil, com jurisdição para atuar na área marítima dos litorais do Rio Grande do Sul, Santa Catarina e Paraná. Porto Alegre, capital do estado, sedia o Comando Militar do Sul (CMS) do Exército Brasileiro, cuja missão é manter a soberania na Região Sul do Brasil. Para tal, conta com cerca de 50 mil militares (25\% do efetivo do Exército Brasileiro) e $75 \%$ dos meios mecanizados existentes na força terrestre. Em Canoas, na Região Metropolitana de Porto Alegre, encontra-se a sede da ALA 3, organização militar responsável pela Força Aérea Brasileira (FAB) nos Estados da Região Sul - Paraná, Santa Catarina e Rio Grande do Sul. As sedes das três forças são acompanhadas por muitas organizações militares espalhadas por todo o território do estado.

A indústria de defesa do Rio Grande do Sul, por sua vez, é bastante diversificada, participando de diferentes projetos estratégicos das Forças Armadas. O Rio Grande do Sul é o terceiro Estado em faturamento e em número de empresas do setor de Defesa (FIPE, 20I4). O Estado conta com importantes empresas fornecedoras das Forças Armadas, como as Empresas Estratégicas de Defesa Taurus (armamento leve), Axur (defesa cibernética) e Agrale (utilitários militares). Além disso, a AEL Sistemas é a principal fornecedora brasileira de aviônicos para a FAB, fazendo parte do projeto dos caças Gripen, sendo responsável pelo Wide Area Display (WAD), pelo Head-Up Display (HUD) e pelo Helmet Mounted Display (HMD). Por sua vez, a KMW Brasil é responsável pela manutenção e modernização de veículos blindados da família Leopard e Gepard adquiridos pelo Exército Brasileiro.

Dada as competências já estabelecidas no Rio Grande do Sul e a sua vocação para assuntos militares, o Governo do Estado vem enfatizando a im-

agenciagabc.com.br/. Acesso em 23 de novembro de 2016.

312 Austral: Revista Brasileira de Estratégia e Relações Internacionais v.7, n.14, Jul./Dez. 2018 
portância estratégica do setor da indústria de defesa, segurança e aeroespacial no desenvolvimento tecnológico e econômico do estado. O embasamento político desta concepção encontra raízes na própria Estratégia Nacional de Defesa (2008), em que a descentralização das cadeias produtivas estratégicas é vista como uma questão de soberania nacional.

Nesse sentido, primeiramente a Agência Gaúcha de Desenvolvimento e Promoção do Investimento (AGDI), entre 20I3 e 20I5, e, posteriormente, a Secretaria do Desenvolvimento Econômico, Ciência e Tecnologia (SDECT), trataram de estabelecer uma parceria cada vez mais colaborativa com o Ministério da Defesa, o Ministério do Desenvolvimento, Indústria e Comércio Exterior (MDIC) e outros ministérios e entidades federais para capilarizar e catalizar as ações do Governo Federal no Estado no que se refere ao setor de defesa e aeroespacial. Como exemplo desta aproximação, é possível citar projeto conjunto entre o MDIC e AGDI para prospectar empresas europeias parceiras na fabricação de satélites de pequeno porte, tanto para aplicações civis quanto militares ${ }^{27}$.

Da mesma forma, a articulação com relevantes entidades que tratam da promoção da indústria de defesa no Rio Grande do Sul, como a ADESM (Agência de Desenvolvimento de Santa Maria) e o COMDEFESA/ FIERGS (Comitê da Indústria de Defesa e Segurança da Federação das Indústrias do Rio Grande do Sul), é um dos focos do Governo do Estado, por meio da SDECT. Foi assinado, em final de 20I4, um convênio entre a ADESM, o COMDEFESA/ FIERGS, o Santa Maria Tecnoparque e o Governo do Estado com o objetivo de criar um arcabouço institucional e financeiro que possibilitasse a execução de ações para promover a indústria de defesa gaúcha ${ }^{28}$. Por meio deste convênio, foi criada a marca "Setor de Defesa \& Segurança Rio Grande do Sul-Brasil", desenvolvido material gráfico promocional e estabelecida uma estratégia conjunta.

Um amplo leque de ações foi executado em 2015 no guarda-chuva institucional criado pelo convênio. Em abril, houve a participação com estande institucional na Feira LAAD Defesa \& Segurança, a mais importante feira do setor de defesa da América Latina, que ocorre a cada dois anos no Rio de

\footnotetext{
27 Diálogos União Europeia e Brasil. "Brasileiros visitam Escócia e Itália para conhecer projetos de fabricação de pequenos satélites”. http://www.sectordialogues.org/noticia/brasileirosvisitam-escocia-e-italia-para-conhecer-projetos-de-fabricacao-de-pequenos-satelites. Acesso em 27 de setembro de 2017 .

28 DefesaNet. "Polo de Defesa de Santa Maria". http://www.defesanet.com.br/bid/ noticia/I8289/Santa-Maria---Polo-de-Defesa--um-ano-de-atuacao-e-muitos-desafios-pelafrente/. Acesso em 29 de setembro de 2017.
} 
Experiências subnacionais em Políticas de Promoção da Indústria de Defesa: o caso do Rio Grande do Sul

Janeiro $^{29}$. Entre julho e setembro, ocorreu o Ciclo de Palestras de Mobilização da Indústria de Defesa do Rio Grande do Sul. Durante três eventos, ocorridos em Santa Maria (com temática focada em simuladores e defesa cibernética ${ }^{30}$ ), em Porto Alegre (aeroespacial ${ }^{3 \mathrm{I}}$ ) e em Caxias do Sul (fornecimento para as Forças Armadas $^{32}$ ), foram feitas 40 palestras, contanto com cerca de 340 participantes. Finalmente, em novembro aconteceu o II Seminário Internacional de Defesa (SEMINDE) em Santa Maria. O evento reuniu cerca de 250 participantes, dentre eles, empresários, militares, representantes do poder público e de instituições vinculadas ao setor, pesquisadores e imprensa especializada para discussões sobre as oportunidades no setor de defesa do Brasil33.

Um importante mecanismo de fomento ao $P \& D$ e à inovação são os Editais de ciência e tecnologia da SDECT. Desde 20I5, a defesa e o aeroespacial entraram como tema prioritário nesses editais. Em 20I5, foram fomentados mais de I4 milhões de reais em diversos projetos. Especificamente, neste ano, não houve nenhum projeto de defesa contemplado. Entretanto, em 2013, o parque de Santa Maria foi contemplado com R\$ 2 milhões para montar uma estrutura de alta tecnologia para o desenvolvimento de simuladores focados na área da indústria de defesa ${ }^{34}$.

Há, também, políticas públicas no Rio Grande do Sul relevantes para a criação de ambiente de negócios mais propício à cooperação, inovação e competitividade das empresas locais, como é o caso do programa dos Arran-

29 Diário de Santa Maria. "Representantes do Polo de Defesa de Santa Maria participarão de feira internacional no Rio de Janeiro". http://diariodesantamaria.clicrbs.com.br/rs/economiapolitica/noticia/2015/03/representantes-do-polo-de-defesa-de-santa-maria-participarao-defeira-internacional-no-rio-de-janeiro-4726946.html. Acesso em 29 de setembro de 2017.

30 Rio Grande do Sul. "Indústria de Defesa gaúcha promove ciclo de mobilização em Santa Maria”. http://www.rs.gov.br/conteudo/221330/industria-de-defesa-gaucha-promove-ciclo-demobilizacao-em-santa-maria. Acesso em 29 de setembro de 2017.

3I Agência de Desenvolvimento de Santa Maria. "Setor de Defesa e Segurança do Rio Grande do Sul promove workshop aeroespacial no Tecnopuc". http://adesm.org.br/noticias/setor-de-defesa-seguranca-rio-grande-sul-promove-workshop-aeroespacial-tecnopuc. Acesso em 29 de setembro de 2017.

32 DefesaNet. Seminário de Fornecimento para as Forças Armadas. http://www.defesanet. com.br/bid/noticia/20106/COMDEFESA-FIERGS----Seminario-de-fornecimento-para-asForcas-Armadas/. Acesso em 29 de setembro de 2017.

33 Infodefensa. Seminário Internacional de Defesa de Santa Maria. http://www.infodefensa. com/latam/20I5/09/26/noticia-seminario-internacional-defesa-santa-maria.html. Acesso em 29 de setembro de 2017 .

34 ADESM. Convênio destina mais de 2 milhões de reais para implementação de centro de desenvolvimento de simuladores no Santa Maria Tecnoparque. http://adesm.org.br/uncategorized/convenio-destina-mais-de-2-milhoes-de-reais-para-implementacao-de-centro-de-desenvolvimento-de-simuladores-santa-maria-tecnoparque. Acesso em 29 de setembro de 2017.

314 Austral: Revista Brasileira de Estratégia e Relações Internacionais v.7, n.14, Jul./Dez. 2018 
jos Produtivos Locais (APLs). O Estado possui forte histórico de políticas de promoção de cooperação entre empresas, sendo este um programa bem consolidado de fomento às economias locais. Atualmente, o Governo do Estado, por meio da SDECT, fomenta cerca de quinze APLs, sendo que mais de 40 já estão estabelecidos no Rio Grande do Sul. O APL de Defesa de Santa Maria foi reconhecido em $2015^{35}$ e foi contemplado com recursos para aprimoramento de sua governança, no valor de R 150 mil, com o intuito de: contratar um gestor e assistentes para o gerenciamento do APL; adquirir infraestrutura para a equipe de gestão; obter subsídios para reuniões de articulação, palestras e eventos de capacitação de empresas; e participar em feiras empresariais, como foi o caso da participação na BID de $20 \mathrm{o} 6$.

Finalmente, a SDECT, por meio da Diretoria de Promoção Comercial e Assuntos Internacionais, conta com três importantes programas de apoio às empresas que podem ser utilizados pela indústria de defesa local. O Programa de Apoio à Participação de Empresas Gaúchas em Feiras Internacionais, criado em 2000 , tem amplo histórico de apoio a milhares de empresas gaúchas que buscam internacionalizar-se e expandirem suas exportações. Em 2016, o programa apoiou quatro empresas gaúchas do setor de defesa para exporem seus produtos na Conferência de Simulação e Tecnologia Militar (CSTM) em Brasília ${ }^{36}$. Além do programa de feiras, também há o programa InvestRS, um convênio firmado entre a SDECT e a FIERGS para executar atividades conjuntas de atração de investimentos para Rio Grande do Sul. Entre os setores estratégicos elencados para ações proativas de atração de investimentos, está o de defesa, aeroespacial e segurança. Ademais, o programa tem como meta o apoio a empresas gaúchas que estejam buscando parceiros internacionais, tanto para captação de recursos financeiros, quanto para desenvolvimento tecnológico conjunto e para o estabelecimento de parcerias comerciais.

\section{Conclusões}

Este artigo teve como objetivo fundamental demonstrar as iniciativas do Governo do Estado do Rio Grande do Sul para a promoção da indústria de defesa gaúcha. Para tanto, buscamos revisar brevemente os principais concei-

35 ADESM. "Mais um APL para Santa Maria”. Acesso em 29 de setembro de 20I7. http:// adesm.org.br/noticias/mais-um-arranjo-produtivo-local-para-santa-maria-apl-polo-de-defesareconhecido-pelo-governo-estado.

36 Rio Grande do Sul. "Conferência com foco em simulação termina nesta quinta feira em Brasília”. Acesso em 29 de setembro de 20I7. http://www.rs.gov.br/conteudo/240889/ conferencia-com-foco-em-simulacao-termina-nesta-quinta-feira-em-brasilia/termosbusca ${ }^{*}$. 
Experiências subnacionais em Políticas de Promoção da Indústria de Defesa: o caso do Rio Grande do Sul

tos e aspectos teóricos que envolvem as políticas industriais de defesa, assim como exemplificar políticas públicas promovidas por outras entidades subnacionais pelo mundo. Tal caminho metodológico foi traçado para reforçar a ideia de que é possível e necessário que o ente subnacional (estados e municípios, no caso brasileiro) se envolva, em conjunto com o Estado Nacional, na promoção da indústria de defesa, tanto servindo como um facilitador e catalisador das iniciativas nacionais na região quanto agindo como protagonista na execução de políticas públicas específicas para a realidade local.

Os exemplos trazidos na segunda seção do artigo buscaram demonstrar que políticas públicas voltadas para o fortalecimento da indústria de defesa em nível subnacional não são exclusividade de países desenvolvidos, nem mesmo daqueles que fazem parte do grupo seleto que contam com as principais prime contractors globais. A França é o único exemplo que trouxemos de um país desenvolvido e tradicional fabricante de produtos de defesa. Já Canadá e Austrália são países com arranjos industriais bem desenvolvidos e tecnologicamente avançados, mas não se encaixam nas categorias de líderes da indústria de defesa. Ainda que com realidades distintas, há casos de sucesso que podem ser replicados, com os devidos ajustes, à realidade brasileira.

Os casos sul-africano, indiano e mexicano, mais próximos do contexto do Brasil, demonstram que as atividades dos estados e províncias podem ter papel muitíssimo relevante para a consolidação da indústria de defesa nacional. A articulação entre a estratégia nacional de defesa e os projetos subnacionais de desenvolvimento precisa ser estreita para que a indústria de defesa encontre ambiente propício para florescer.

O Rio Grande do Sul conta com grande potencial para se fortalecer enquanto ator subnacional relevante na indústria de defesa. Certa competição existe os estados da Federação para a atração de grandes projetos industriais e tecnológicos, e, no caso específico da defesa, os estados da região sudeste são os candidatos naturais a receber tais investimentos. Entretanto, as atuais modificações na política da SUDENE (Superintendência de Desenvolvimento do Nordeste) e da SUDECO (Superintendência de Desenvolvimento do Centro-Oeste - SUDECO), autorizando o financiamento de indústrias de defesa com os fundos constitucionais do Nordeste ${ }^{37}$ e Centro-Oeste ${ }^{38}$, colocam os estados

37 DefesaNet. "Indústrias de Defesa contarão com acesso ao Fundo de Desenvolvimento do Nordeste." Acesso em 4 de outubro de 20I7. http://www.defesanet.com.br/bid/noticia/26573/ Industrias-de-Defesa-contarao-com-acesso-ao-Fundo-Desenvolvimento-do-Nordeste\%28FDNE\%29-para-se-instalarem-na-regiao-/.

38 Brasil. Ministério Da Defesa. "Indústrias de defesa que quiserem se instalar no centro-oeste contarão com apoio de fundo constitucional". Acesso em 04 de outubro de 20I7. http://www. defesa.gov.br/noticias/35453-industrias-de-defesa-que-quiserem-se-instalar-no-centro-oeste-

316 Austral: Revista Brasileira de Estratégia e Relações Internacionais v.7, n.14, Jul./Dez. 2018 
dessas regiões em uma posição vantajosa. Frente a esse cenário, o Governo do Estado, em parceria com os atores regionais, precisa rapidamente articular políticas públicas focadas no financiamento específico para a defesa e no incentivo à pesquisa e inovação, para atrair novas empresas, mas, principalmente, para manter as que no estado já estão.

\section{REFERÊNCIAS}

A Razão. "Polo de Defesa de Santa Maria é reconhecido como APL". Acesso em 23 de novembro de 20I6. http://www.arazao.com.br/noticia/70693/polo-de-defesa-de-santa-maria-reconhecido -como-apl/ .

ADESM. "Convênio destina mais de 2 milhões de reais para implementação de centro de desenvolvimento de simuladores no Santa Maria Tecnoparque". Acesso em 29 de setembro de 20I7. http://adesm.org. br/uncategorized/convenio-destina-mais-de-2-milhoes-de-reais-para-implementacao-de-centro-de-desenvolvimento-de-simuladores-santa-maria-tecnoparque.

ADESM. "Mais um APL para Santa Maria". Acesso em 29 de setembro de 20I7. http://adesm.org.br/noticias/mais-um-arranjo-produtivo-local-para-santa-maria-apl-polo-de-defesa-reconhecido-pelo-governo-estado.

Aerocluster Queretaro. "Mapa de ruta del sector aeroespacial de la región de Queretaro". Acesso em II de agosto de 20I7. http://aeroclusterqueretaro.mx/images/PDF/Mapa-de-ruta-del-Sector-Aeroespacial-de-laRegin-de-Quertaro-c_portada-I0022016.pdf.

Aero Montreal. "Québec Government's 2016-20I7 Budget". Acesso em ro de julho de 20I7. https://www.aeromontreal.ca/release-quebec-government-2016-I7-budget.html.

Aero Montreal. "Reports and Documents". Acesso em II de julho de 2017. https://www.aeromontreal.ca/reports-and-documents.html.

Aero Montreal. Site institucional. Acesso em Io de julho de 20I7. https:// www.aeromontrealr.ca/.

Aerospace Industries Association of Canada (AIAC). Industry Statistics. Acesso em II de julho de 20I7. http://aiac.ca/industry-statistics/.

Aerospace Valley. Site institucional. Acesso em in de julho de 20I7. http:// www.aerospace-valley.com.

contarao-com-financiamento-de-fundo-constitucional. 
Experiências subnacionais em Políticas de Promoção da Indústria de Defesa: o caso do Rio Grande do Sul

África do Sul. Department of Trade and Industry. CAV Presentation: Portfolio Committee on Trade and Industry CAV CEO, 20I5. Acesso em: 05 de outubro de 20I6. https://www.thedti.gov.za/ parliament/ 2015/CAV. pdf.

África do Sul. Department of Trade and Industry. CAV Presentation: Portfolio Committee on Trade and Industry CAV CEO, 2015. Acesso em 05 de outubro de 20I6. https://www.thedti.gov.za/ parliament/ 2015/CAV. pdf.

Agência Brasileira de Desenvolvimento Industrial. "Programa estimula inovação na indústria aeronáutica”. Acesso em oI de dezembro de 2016. http://www.abdi.com.br/Paginas/noticia_detalhe.aspx?i=4097.

Agência de Desenvolvimento de Santa Maria. "Setor de Defesa e Segurança do Rio Grande do Sul promove workshop aeroespacial no Tecnopuc". Acesso em 29 de setembro de 20I7. http://adesm.org.br/noticias/ setor-de-defesa-seguranca-rio-grande-sul-promove-workshop-aeroespacial-tecnopuc.

Agência de Desenvolvimento Econômico Grande ABC. Site Institucional. Acesso em 23 de novembro de 20I6. http://www.agenciagabc.com. br/.

Australia. "Department of State Development - Clusters". Acesso em io de julho de 20I7. http://statedevelopment.sa.gov.au/industry/innovation/clusters.

Berkok, Ugurhan, Christopher Penney and Karl Skogstad. Defence Industrial Policy Approaches and Instruments. 20I2. Acesso em 22 de fevereiro de 20I6. http://aerospacereview.ca/eic/site/o6o.nsf/vwapj/ Def_Ind_Pol_Approaches_-_Final_Draft_-_July_I3.pdf/\$FILE/Def_ Ind_Pol_Approaches_-_Final_Draft_-_July_I3.pdf.

Bitzinger. "New ways of thinking about the global arms industry: dealing with 'limited autarky". Strategic Insights. Australian Strategic Policy Institute. November, 20I5. Acesso em 30 de janeiro de 20I7. https://www. aspistrategist.org.au/new-ways-of-thinking-about-the-global-arms-industry-dealing-with-limited-autarky/.

Brasil. Ministério da Defesa. Estratégia Nacional de Defesa. Brasília, 2008.

Brasil. Ministério Da Defesa. "Indústrias de defesa que quiserem se instalar no centro-oeste contarão com apoio de fundo constitucional". Acesso em 04 de outubro de 20I7. http://www.defesa.gov.br/noticias/35453-industrias-de-defesa-que-quiserem-se-instalar-no-centro-oeste-contarao-com-financiamento-de-fundo-constitucional.

CECOMPI. “Aerospace Cluster”. Acesso em 23 de novembro de 20I6. http://

318 Austral: Revista Brasileira de Estratégia e Relações Internacionais v.7, n.14, Jul./Dez. 2018 
www.cecompi.org.br/aero/en/aerospace-cluster.

Defence South Australia. "South Australia Defence Strategy 2025”. Acesso em Io de julho 20I7. http://www.defencesa.com/about-defence-sa/ south-australias-defence-strategy-2025.

DefesaNet. "Indústrias de Defesa contarão com acesso ao Fundo de Desenvolvimento do Nordeste". Acesso em 04 de outubro de 20I7. http:// www.defesanet.com.br/bid/noticia/26573/Industrias-de-Defesa-contarao-com-acesso-ao-Fundo-Desenvolvimento-do-Nordeste-\%28FDNE\%29-para-se-instalarem-na-regiao-/.

DefesaNet. "Polo de Defesa de Santa Maria”. Acesso em 29 de setembro de 20I7. http://www.defesanet.com.br/bid/noticia/18289/Santa-Maria--Polo-de-Defesa--um-ano-de-atuacao-e-muitos-desafios-pela-frente/.

DefesaNet. Seminário de Fornecimento para as Forças Armadas - COMDEFESA FIERGS. Acesso em 29 de setembro de 20I7. http://www.defesanet.com.br/bid/noticia/20106/COMDEFESA-FIERGS----Seminario-de-fornecimento-para-as-Forcas-Armadas/.

Diálogos União Européia e Brasil. "Brasileiros visitam Escócia e Itália para conhecer projetos de fabricação de pequenos satélites”. Acesso em 27 de setembro de 2017. http://www.sectordialogues.org/noticia/ brasileiros-visitam-escocia-e-italia-para-conhecer-projetos-de-fabricacao-de-pequenos-satelites.

Diário de Santa Maria. "Representantes do Polo de Defesa de Santa Maria participarão de feira internacional no Rio de Janeiro". Acesso em 29 de setembro de 20I7. http://diariodesantamaria.clicrbs.com.br/rs/ economia-politica/noticia/2015/03/representantes-do-polo-de-defesa-de-santa-maria-participarao-de-feira-internacional-no-rio-de-janeiro-4726946.html.

Dunne, Paul. 2009. "Developments in the Global Arms Industry from the End of the Cold War to the mid-20oos". In: The Modern Defense Industry: political, economic and Technological issues. by Richard Bitzinger (Ed.). Santa Barbara: Praeger Security International.

El Financiero. "Crece I70\% la IED de equipo aeroespacial em Querétaro". El Financiero. Acesso em II de agosto de 20I7.http://www.elfinanciero. com.mx/bajio/crece-I7o-la-ied-de-equipo-aeroespacial-en-queretaro. html.

El Financiero. "El cluster aeronáutico de Queretaro ya vuela solo”. El Financiero. Acesso em II de agosto de 20I7. http://www.elfinanciero.com.mx/ economia/el-cluster-aeronautico-de-queretaro-ya-vuela-solo.html.

Gardes, Nathalie, Isabelle Dostaler, Céline Barredy and Corrine Gour- 
Experiências subnacionais em Políticas de Promoção da Indústria de Defesa: o caso do Rio Grande do Sul

mel-Rouger. Aerospace Cluster and Competitiveness Poles: A France-Quebec Comparison. Journal of Traffic and Transportation Engineering. January 2015.

Hall, Peter, Stefan Markowski and Robert Wylie. 20Io. Defence Procurement and Industry Policy: a small country perspective. Nova York: Routledge.

Helfrich, Kim. "Nothing happening at Centurion Aerospace Village DA maintains". DefenceWeb. I8 de setembro de 2015. Acesso em o5 de outubro de 20I6. http://www.defenceweb.co.za/index.php?option=com_con tent\&view=article\&id=40786:nothing-happening-at-centurion-aerospace-village-da-maintains \&catid=35:Aerospace\&Itemid=107.

Hindustan Times. “Young entrepreneur to set up Punjab's Ist defence, aerospace parts unit". Acesso em 03 de agosto de 20I7. http://www.hindustantimes.com/punjab/young-entrepreneur-to-set-up-punjab-sfirst-defence-aerospace-parts-unit/story-FfWVpk8vllacU2dXfwp6ıK. htm.

Índice Político. "Ubican a Querétaro como el Paraíso para la Industria Aeroespacial de México". Acesso em II de agosto de 20I7. http://www. indicepolitico.com/ubican-a-queretaro-como-el-paraiso-para-la-industria-aeroespacial-de-mexico/.

Infodefensa. Seminário Internacional de Defesa de Santa Maria. Acesso em 29 de setembro de 20I7. http://www.infodefensa.com/ latam/20I5/09/26/noticia-seminario-internacional-defesa-santa-maria.html.

Market Wired. “AeroMontreal Receives \$I,584,I50 in Funding from Government of Canada". Acesso em Io de julho de 20I7. http://www.marketwired.com/press-release/aero-montreal-receives-1584I50-in-funding-from-government-of-canada-I906355.htm/.

Mello, Regine de. 20I5. Indústria de Defesa e Desenvolvimento Estratégico: estudo comparado França-Brasil. Brasília: FUNAG.

Mota, Rui Martins, e Gustavo Assad de Praga Rodrigues. 20I2. "Debatendo o Fortalecimento da BID do Brasil”. In: VI Encontro Nacional da Associação Brasileira de Estudos de Defesa e I Encontro Sul-americano de Defesa. São Paulo: Anais do VI ENABED, 2012.

Observatório Brasileiro de APLs. "Plano de Ação do Polo de Defesa de Santa Maria”. Acesso em 23 de novembro de 20I6. http://portalapl.ibict. br/export/sites/apl/galerias/Biblioteca/APL_de_Defesa_-_Plano de_Axo_do_Polo_de_Defesa_de_Santa_Maria_20I5.pdf.

Observatório Brasileiro de APLs. Site institucional. Acesso em 22 de novembro de 20I6. http://portalapl.ibict.br/menu/itens_menu/gtp_apl/

320 Austral: Revista Brasileira de Estratégia e Relações Internacionais v.7, n.14, Jul./Dez. 2018 
gtp_apl.html.

Oliveira, Susan Elizabeth Martins Cesar de. 20I5. Cadeias globais de valor e os novos padrões de comércio internacional: estratégias de inserção de Brasil e Canadá. Brasília: FUNAG.

Parque Tecnológico de São José dos Campos. "Quem Somos”. Acesso em 23 de novembro de 20I6. http://www.pqtec.org.br/conheca-o-parque/ quem-somos.php.

Punjab. "Invest in Punjan Aerospace and Defence sector". Aerospace and Defence. Acesso em o3 de agosto de 20I7. http://investpunjab.gov.in/ Content/documents/Collateral/AerospaceandDefence_Col.pdf.

Rio Grande do Sul. "Conferência com foco em simulação termina nesta quinta feira em Brasília”. Acesso em 29 de setembro de 20I7. http:// www.rs.gov.br/conteudo/240889/conferencia-com-foco-em-simulacao-termina-nesta-quinta-feira-em-brasilia/termosbusca $=*$.

Rio Grande do Sul. "Indústria de Defesa gaúcha promove ciclo de mobilização em Santa Maria”. Acesso em 29 de setembro de 2017. http://www. rs.gov.br/conteudo/221330/industria-de-defesa-gaucha-promove-ciclo-de-mobilizacao-em-santa-maria.

Tellis, Ashley et al. 2000. Measuring National Power in the Postindustrial Age. Santa Monica: Rand Corp.

The Citzen. "R9om spent on Centurion Aerospace Village, nothing on site". The Citzen. I7 de setembro de 2015. Acesso em 05 de outubro de 20I6. http://citizen.co.za/775690/rgom-spent-on-centurion-aerospace-village-nothing-on-site/. 
Experiências subnacionais em Políticas de Promoção da Indústria de Defesa: o caso do Rio Grande do Sul

\section{RESUMO}

Este artigo tem como objetivo principal apresentar iniciativas do Governo do Estado do Rio Grande do Sul para a promoção da indústria de defesa gaúcha nos últimos anos. As entidades subnacionais tem um importante papel para o fortalecimento da indústria de defesa nacional e, por meio da formulação e implementação de políticas públicas bem definidas, são capazes de exercer a função de facilitadores e catalisadores das iniciativas nacionais em nível local. Este artigo busca trazer exemplos que demonstrem as diversas políticas públicas que podem ser implementadas por entes subnacionais tanto em países desenvolvidos (Austrália, Canadá e França) quanto em desenvolvimento (África do Sul, Índia e México), comparando-as com o que vem sendo feito no caso brasileiro.

\section{PALAVRAS-CHAVE}

Indústria de Defesa; Entidades subnacionais; Rio Grande do Sul.

Recebido em 30 de jultho de 2018. Aprovado em 25 de setembro de 2018. 